\title{
Phentolamine for vasodilator therapy in left ventricular failure complicating acute myocardial infarction \\ Haemodynamic study
}

\author{
Cl. Perret, J.-P. Gardaz, M. Reynaert, F. Grimbert, and J.-F. Enrico \\ From the Institute of Pathophysiology and Intensive Therapy Unit, Medical Department, \\ University Hospital, Lausanne, Switzerland
}

In 15 patients with acute myocardial infarction associated with signs of left ventricular dysfunction, phentolamine was infused intravenously in a dose of $10 \mathrm{mg}$ per hour. This therapy induced a substantial reduction in mean right atrial pressure from 10 to $7 \mathrm{mmHg}(1.3$ to $0.9 \mathrm{kPa})(P<0.001)$, and in pulmonary capillary wedge pressure from 20 to $13 \mathrm{mmHg}(2.7$ to $\mathrm{I.7} \mathrm{kPa})(P<0.001)$. The cardiac index increased from 2.5 to $3.0 \mathrm{l} / \mathrm{min}$ per $\mathrm{m}^{2}(P<0.00 \mathrm{I})$ accompanied by a fall in both the systemic and pulmonary vascular resistances $(P<0.00 I)$. On the other hand, the mean stroke work index did not change significantly after phentolamine, because of the combined effects of the increased cardiac output and of the lowered systemic vascular resistance. With the dose used the mean arterial pressure decreased from II $1299 \mathrm{mmHg}(14.9$ to $13.2 \mathrm{kPa})(P<0.00 \mathrm{I})$. No adverse effects attributable to the drug treatment were noted.

Benefits of this treatment are probably related to reduction in the impedance to left ventricular ejection and possibly to its relaxant effect on the venous tone. The drug may also improve subendocardial perfusion by decreasing left diastolic ventricular pressure. This could possibly limit extension of necrosis. Thus vasodilator therapy appears to be of particular interest in left ventricular failure complicating acute myocardial infarction, where inotropic agents may be contraindicated.

Left heart failure is a frequent complication of acute myocardial infarction. The treatment of this cardiac insufficiency has hitherto been approached in three different ways: administration of positive inotropic agents, with the aim of increasing the contractility of the remaining unaffected myocardium; vasopressor amines, with the aim of improving coronary perfusion, thus limiting the extent of the infarction; and diuretics, in order to reduce the circulatory volume, thus reducing pulmonary congestion.

These forms of treatment have, in fact, proved disappointing: cardiac output is not always improved by digitalis preparations (Malmcrona, Schröder, and Werkö, 1966; Cohn, Tristani, and Khatri, 1969; Hodges et al., 1972; Rahimtoola et al., 1972), vasopressor amines increase the afterload on an already failing myocardium (Cohn, 1973), and, finally, diuretics can lead to a further fall in cardiac output because of a reduction in

Received II October 1975. venous return (Cohn et al., 1972; Dikshit et al., 1973).

In earlier work (Enrico, Poli, and Perret, I97I) we were able to observe the beneficial effect of vasodilator therapy in pulmonary oedema resistant to the classic forms of therapy. In hypertensive patients with myocardial infarction a reduction of the afterload, obtained with phentolamine infusion, resulted in the rapid disappearance of pulmonary congestion while at the same time correcting the lactic acidosis secondary to tissue anoxia. Some recent studies have confirmed the benefits of vasodilator therapy in severe chronic cardiac insufficiency (Majid, Sharma, and Taylor, 1971), and in myocardial infarction (Franciosa et al., 1972; Kelly et al., 1973; Chatterjee et al., 1973). The present study was undertaken to determine the haemodynamic effects of phentolamine, administered in low doses with the aim of reducing the afterload without excessively lowering the coronary infusion pressure. 


\section{Subjects and methods \\ Selection of patients}

Studies were made on 15 patients, II men and 4 women, for a period of 24 hours after the onset of symptoms of acute myocardial infarction, in the Intensive Care Unit of the Medical Department of the University of Lausanne. The patients were aged between 34 and 77 years, the average age being $6 \mathrm{I}$ years.

The criteria for the diagnosis of acute myocardial infarction included a suggestive clinical history, typical electrocardiographic abnormality, and characteristic increases in the serum aspartate aminotransferase, serum alanine transaminase, and creatinine phusphokinase activity in serial blood samples over the first three days.

Before vasodilator therapy, all but two patients had signs of cardiac failure viz: a fourth heart sound gallop rhythm, râles at the lung bases, and radiological signs of pulmonary congestion (Table I). All these patients had first received oxygen and analgesics. No patients received diuretics or digitalis before administration of phentolamine. Informed consent was obtained from the patients.

\section{Haemodynamic measurements}

In all patients right atrial (RA), mean pulmonary arterial (MPA), and pulmonary capillary wedge (PCW) pressures were recorded through a balloon-tip triple-lumen $7 \mathrm{~F}$ catheter (Ganz and Swan, 1972). The catheter was introduced via an antecubital or an internal jugular vein, by means of a venous $8 \mathrm{~F}$ percutaneous catheter introducer. Pressures were measured with Statham P230B transducers, and recorded on a three-channel thermal writing recorder (Cardiopan $3 \mathrm{~T}$, Philips). The common zero reference level for all pressures was set at $4 \mathrm{~cm}$ below the sternal angle, with the patient in the supine position.

Arterial pressures were measured in several patients by an indwelling brachial artery $3 \mathrm{~F}$ 'teflon' catheter inserted percutaneously. In the other cases arterial pressure was measured by the normal cuff from which the mean arterial pressure (MA) was calculated (diastolic pressure plus one-third of the pulse pressure).

Cardiac output (CO) was measured in triplicate by the thermodilution technique using the triple-lumen balloon catheter (Ganz and Swan, 1972). A direct display of cardiac output was provided by a computer (9500 cardiac output computer ${ }^{1}$ ). The results were verified by direct planimetry of the thermal curves.

The haemodynamic variables were calculated from the basic data, as follows:

Cardiac index (CI):

$$
\frac{\text { Cardiac output (CO) }}{\text { body surface area (BSA) }}\left(1 / \mathrm{min} \text { per } \mathrm{m}^{2} \mathrm{BSA}\right)
$$

Stroke volume index (SVI): $\frac{\mathrm{SV}}{\mathrm{BSA}}\left(\mathrm{ml}^{\mathrm{p}}\right.$ per $\left.\mathrm{m}^{2} \mathrm{BSA}\right)$

Stroke work index (SWI):

$$
\text { SVI } \times(\mathrm{MA}-\mathrm{PCW}) \times 0.0136\left(\mathrm{~g} \mathrm{M} \text { per } \mathrm{m}^{2} \mathrm{BSA}\right)
$$

Systemic vascular resistance index (SVRI):

$$
\frac{\mathrm{MA}-\mathrm{RA}}{\mathrm{CI}}\left(\mathrm{mmHg} / 1 \mathrm{~min}^{-1} \text { per } \mathrm{m}^{2} \mathrm{BSA}\right)
$$

Pulmonary vascular resistance index (PVRI):

$$
\frac{\mathrm{MPA}-\mathrm{PCW}}{\mathrm{CI}}\left(\mathrm{mmHg} / 1 \mathrm{~min}^{-1} \text { per } \mathrm{m}^{2} \mathrm{BSA}\right)
$$

\section{Procedure}

After the balloon had been placed in the correct position, confirmed radiologically, and the patient was in a steady state, as defined by serial haemodynamic measurements, phentolamine, diluted in a solution of 5 per cent dex-

${ }^{1}$ Edwards Laboratories, Santa Ana, Calif., U.S.A.

TABLE I Clinical data

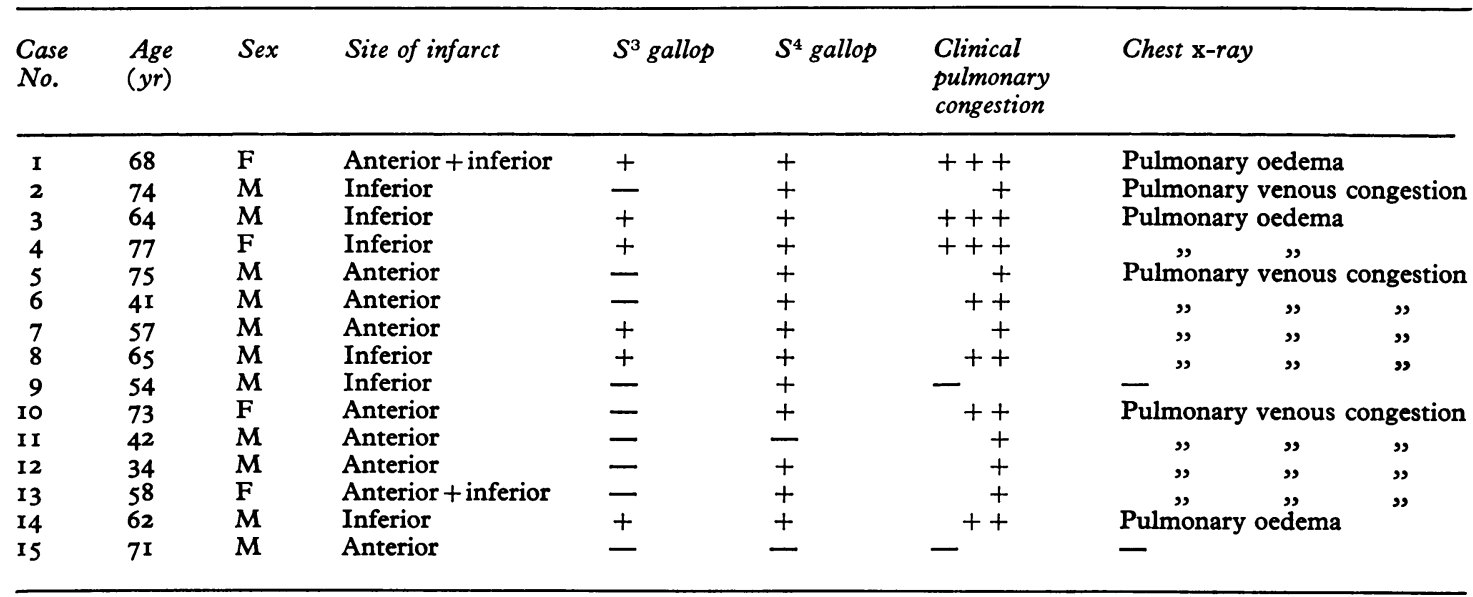

Clinical pulmonary congestion: $+=$ mild; $++=$ severe; $+++=$ pulmonary oedema. $S^{3}=$ Third heart sound; $S^{4}=$ Fourth heart sound. 
trose, was administered into the right atrium at a rate of ro $\mathrm{mg}$ per hour, for one hour.

All the measurements were repeated at the end of each phentolamine infusion. In 5 patients (Cases $3,6,7$, 8 , and 10), the same procedure was repeated once or twice with a minimum interval of one hour between two successive tests.

\section{Results}

The results of the haemodynamic studies are presented in Table 2. The values were measured in steady state before and after a one-hour phentolamine infusion. Response was indicated by an average increase in the cardiac index of $0.5 \mathrm{l} / \mathrm{min}$ per $\mathrm{m}^{2}$ BSA, secondary to simultaneous increases in both the heart rate and stroke index. This increase in cardiac output was accompanied by a reduction in the mean pulmonary capillary wedge and right atrial pressures from $20 \mathrm{mmHg}(2.7 \mathrm{kPa})$ and Io $\mathrm{mmHg}(1.3 \mathrm{kPa})$ to $13 \mathrm{mmHg}(1.7 \mathrm{kPa})$ and
$7 \mathrm{mmHg}(0.9 \mathrm{kPa})$ respectively. The mean pulmonary arterial pressure fell from $32 \mathrm{mmHg}(4.3 \mathrm{kPa})$ to $24 \mathrm{mmHg}$ ( $3.2 \mathrm{kPa}$ ). With the doses used in this study the mean arterial pressure fell, on average, from $112 \mathrm{mmHg}$ (I4.9 $\mathrm{kPa}$ ) to $99 \mathrm{mmHg}$ ( 13.2 $\mathrm{kPa}$. The systemic vascular resistance fell by an average of 25 per cent. All these changes are highly significant $(\mathbf{P}<0.00 \mathrm{I})$. The mean stroke work index, on the other hand, did not change significantly after phentolamine, because of the combined effects of the lowered peripheral vascular resistance and increased cardiac output.

There is a positive correlation between the fall in mean arterial pressure induced by the phentolamine and the initial mean arterial pressure: $r=-0.8 \mathrm{I}$, $P<0.001$. On the other hand, there is no simple relation between the changes in the impedance to ejection or the mean arterial pressure and the initial cardiac index or pulmonary capillary wedge pressure values.

TABLE 2

\begin{tabular}{|c|c|c|c|c|c|c|c|c|c|c|c|c|c|c|c|c|}
\hline \multirow[t]{3}{*}{ Case No. } & \multirow{2}{*}{\multicolumn{2}{|c|}{$\begin{array}{l}\text { Heart rate } \\
\text { (beats } / \text { min) }\end{array}$}} & \multicolumn{8}{|c|}{ Pressures } & \multirow{2}{*}{\multicolumn{2}{|c|}{$\begin{array}{l}\text { Cardiac } \\
\text { index } \\
\left(l / \text { min }^{2}\right. \\
\text { per } m^{2} \\
B S A)\end{array}$}} & \multirow{2}{*}{\multicolumn{2}{|c|}{$\begin{array}{l}\text { Stroke } \\
\text { work } \\
\text { index } \\
\text { ( } \mathrm{g} \mathrm{m} \\
\text { per } m^{2} \\
B S A)\end{array}$}} & \multirow{2}{*}{\multicolumn{2}{|c|}{$\begin{array}{l}\text { Systemic } \\
\text { vascular } \\
\text { resistance } \\
\text { index } \\
\text { (mmHg/l } \\
\min ^{-1} \text { per } \\
\left.m^{2} B S A\right)\end{array}$}} \\
\hline & & & \multicolumn{2}{|c|}{$\begin{array}{l}\text { Mean } \\
\text { arterial } \\
(\mathrm{mmHg})\end{array}$} & \multicolumn{2}{|c|}{$\begin{array}{l}\text { Right } \\
\text { atrium } \\
(\mathrm{mmHg})\end{array}$} & \multicolumn{2}{|c|}{$\begin{array}{l}\text { Mean } \\
\text { pulmonary } \\
\text { arterial } \\
(\mathrm{mmHg})\end{array}$} & \multicolumn{2}{|c|}{$\begin{array}{l}\text { Pulmonary } \\
\text { capillary } \\
\text { wedge } \\
(\mathrm{mmHg})\end{array}$} & & & & & & \\
\hline & $C$ & $P$ & $C$ & $P$ & $C$ & $P$ & $C$ & $P$ & $C$ & $P$ & $C$ & $P$ & $C$ & $P$ & $C$ & $P$ \\
\hline $\mathbf{I}$ & 120 & 124 & 100 & 90 & 13 & 5 & 40 & 30 & 22 & I4 & 1.5 & 1.9 & 13.5 & 16 & 57 & 45 \\
\hline 2 & 112 & 120 & 97 & 88 & 13 & 9 & 38 & 34 & 20 & 18 & 2.7 & 3.1 & 25 & 24 & 31 & 26 \\
\hline 3 a) & 84 & 96 & 98 & 93 & II & 9 & 34 & 30 & 26 & 20 & 2.0 & $3 \cdot 3$ & 24 & 34 & 43 & 26 \\
\hline b) & 80 & 86 & 88 & 92 & 9 & 9 & 34 & 26 & 27 & 15 & 2.6 & 3.0 & 27 & 36 & 30 & 28 \\
\hline c) & 80 & 84 & 93 & 93 & 9 & 7 & 29 & 22 & 20 & 15 & 2.4 & 2.6 & 29 & 33 & 36 & 33 \\
\hline 4 & 85 & 94 & 140 & 127 & 12 & 9 & 38 & 25 & 28 & 16 & 2.5 & 3.1 & 44 & 50 & 52 & 38 \\
\hline 5 & 82 & 96 & I73 & 130 & 8 & 4 & 35 & 25 & 23 & 14 & 3.0 & 3.4 & 74 & 55 & 56 & 37 \\
\hline 6 a) & 82 & 90 & 88 & 84 & 12 & 7 & 30 & 24 & 21 & 12 & 2.7 & 3.7 & $3 \mathrm{I}$ & $4 I$ & 28 & 21 \\
\hline b) & 85 & 90 & 94 & 84 & II & 7 & 32 & 24 & 20 & 12 & 2.8 & 3.7 & 33 & $4 I$ & 29 & $2 I$ \\
\hline 7 a) & 84 & 96 & 127 & 107 & 9 & 5 & 37 & 16 & 18 & 5 & 2.5 & 3.6 & 45 & 51 & 46 & 29 \\
\hline b) & 80 & 86 & 107 & 108 & 7 & 5 & 29 & $2 \mathrm{I}$ & 12 & 7 & 2.5 & 3.0 & $4 \mathrm{I}$ & 47 & 40 & 35 \\
\hline c) & 100 & 108 & 117 & 95 & Io & 8 & 29 & $2 \mathrm{I}$ & 20 & 14 & 2.6 & 3.6 & 34 & 36 & $4 \mathrm{I}$ & 25 \\
\hline 8 a) & 100 & IIO & II5 & IOI & 5 & 5 & 25 & 20 & 15 & IO & 2.2 & 2.6 & 37 & 29 & 49 & 37 \\
\hline b) & 100 & 105 & 120 & 105 & 6 & 5 & 31 & 20 & 17 & II & 2.4 & 2.6 & 34 & 32 & 48 & 38 \\
\hline c) & 96 & 108 & I IO & 107 & 5 & I & 28 & I5 & 18 & 6 & 2.3 & 2.5 & 30 & 33 & 49 & $4 I$ \\
\hline 9 & 52 & 54 & 125 & I I 5 & 8 & 6 & 19 & 15 & I4 & I0 & 1.9 & 2.4 & 56 & 62 & 62 & 46 \\
\hline ro a) & 82 & 96 & IIO & 87 & 14 & 8 & 28 & 29 & 20 & 19 & 2.7 & 3.6 & 40 & 34 & 36 & 22 \\
\hline b) & 88 & 96 & 113 & 87 & II & IO & 22 & 16 & 14 & 10 & 2.5 & 2.6 & 38 & 29 & $4 I$ & 29 \\
\hline I I & 90 & 98 & 90 & 90 & 16 & 13 & 28 & 25 & 20 & 20 & 2.4 & 3.5 & 26 & 34 & 30 & 22 \\
\hline 12 & 84 & 82 & 125 & 107 & 12 & 8 & 40 & 32 & 23 & 15 & 2.7 & 3.2 & 45 & 49 & 42 & $3 I$ \\
\hline 13 & 100 & 100 & 118 & 103 & 9 & 9 & 40 & 36 & 20 & 15 & 2.4 & 2.7 & 32 & 32 & 45 & 36 \\
\hline 14 & 68 & 68 & 90 & 80 & 12 & 7 & 40 & 32 & 27 & 20 & 2.8 & 3.0 & 36 & 35 & 28 & 25 \\
\hline 15 & 125 & 135 & 130 & 108 & 9 & 6 & 34 & 21 & 21 & 10 & 2.3 & 2.5 & 28 & 25 & 52 & $4 I$ \\
\hline Mean & 90 & 97 & 112 & 99 & 10 & 7 & 32 & 24 & 20 & 13 & 2.5 & 3.0 & 36 & 37 & 42 & 32 \\
\hline$\pm \mathrm{SEM}$ & 3.3 & 3.6 & 4.2 & 2.8 & 0.6 & 0.5 & 1.2 & 1.3 & 0.9 & 0.9 & 0.07 & 0.10 & 2.5 & 2.3 & 2.1 & I.6 \\
\hline$\overline{\mathbf{P}}<$ & 0.001 & & 0.001 & & 0.001 & & 0.001 & & 0.001 & & 0.001 & & NS & & 0.001 & \\
\hline
\end{tabular}

Conversion factor from Traditional Units to SI Units: I $\mathrm{mmHg} \approx 0.133 \mathrm{kPa}$.

$\mathrm{C}=$ Control $\mathbf{P}=$ Phentolamine $; \mathrm{S}=$ Survived $\mathbf{D}=$ Died. 
In Fig. I the changes in the cardiac index in relation to the pulmonary capillary wedge pressure after phentolamine can be seen. In all but one patient (Case II) the increased output was accompanied by a reduction in the pulmonary capillary wedge pressure. However, if one studies the changes in the stroke work index in relation to the pulmonary capillary wedge pressure (Fig. 2), it can be seen that the significant increase in the cardiac index is not always accompanied by an increase in stroke work. In 3 patients (Cases 5,8 , and ro) there was a slight reduction in the stroke work index. Overall, the same stroke work is obtained with a lower filling pressure.

In 5 patients the test was carried out twice (Cases 6 and 10) or three times (Cases 3, 7, and 8). The second and third tests were carried out between I and 24 hours after the end of the previous phentolamine infusion. The haemodynamic response to the vasodilator is comparable in each test (Fig. 3). The

\begin{tabular}{|c|c|c|}
\hline \multicolumn{2}{|c|}{$\begin{array}{l}\text { Pulmonary } \\
\text { vascular } \\
\text { resistance } \\
\text { index } \\
\left(\text { mmHg/l min }{ }^{-1}\right. \\
\left.\text { per } m^{2} B S A\right)\end{array}$} & \multirow[t]{2}{*}{ Evolution } \\
\hline$C$ & $P$ & \\
\hline 12 & 8 & $S$ \\
\hline 7 & 5 & $\mathrm{D}$ \\
\hline 4 & 3 & $S$ \\
\hline 4 & 3 & \\
\hline 4 & 3 & \\
\hline 4 & 3 & $\mathbf{S}$ \\
\hline 4 & 3 & S \\
\hline 3 & 3 & $S$ \\
\hline 4 & 3 & \\
\hline 8 & 3 & $S$ \\
\hline $\begin{array}{l}7 \\
4\end{array}$ & $\begin{array}{l}5 \\
2\end{array}$ & \\
\hline 4 & 4 & $\mathbf{S}$ \\
\hline 6 & 3 & \\
\hline 4 & 3 & \\
\hline 3 & 2 & $\mathbf{S}$ \\
\hline 3 & 3 & $\mathbf{S}$ \\
\hline 3 & 2 & \\
\hline 3 & I & $\mathbf{S}$ \\
\hline $\begin{array}{l}5 \\
8\end{array}$ & $\begin{array}{l}5 \\
8\end{array}$ & $\begin{array}{l}S \\
S\end{array}$ \\
\hline 5 & 4 & D \\
\hline 6 & 4 & S \\
\hline 4.9 & 3.6 & \\
\hline 0.5 & 0.4 & \\
\hline 0.001 & & \\
\hline
\end{tabular}

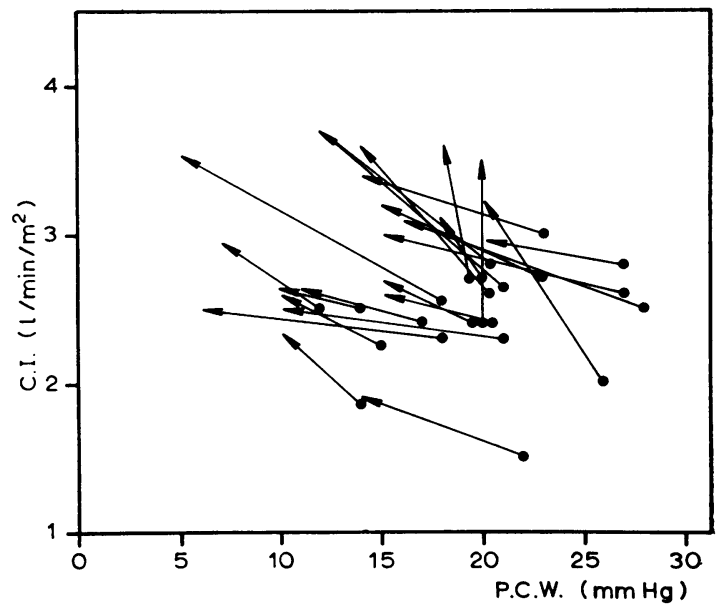

FIG. I Individual changes in cardiac index (CI) and the pulmonary capillary wedge (PCW) pressure after phentolamine intravenous infusion. The dots represent the baseline recordings and the arrow heads. the recordings at the end of the infusion. (I $\mathrm{mmHg}=$ $0.133 \mathrm{kPa}$.)

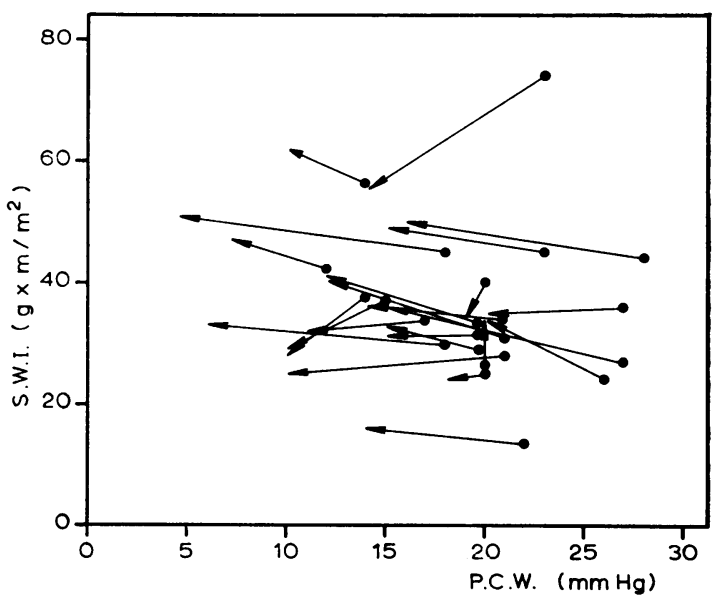

FIG. 2 Individual changes in the stroke work index (SWI) and pulmonary capillary wedge (PCW) pressure after phentolamine intravenous infusion. The dots represent the baseline recordings and the arrow heads the recordings at the end of the infusion. (I $\mathrm{mmHg}=$ $0.133 \mathrm{kPa}$.)

effect of phentolamine was seen to wear off in the 30 minutes after the end of the infusion.

The phentolamine infusions were well tolerated. No patient had any chest pain, nausea, or vomiting. No arrhythmia was observed. Of the 15 patients studied, 2 died, I from irreversible cardiac insuffi- 

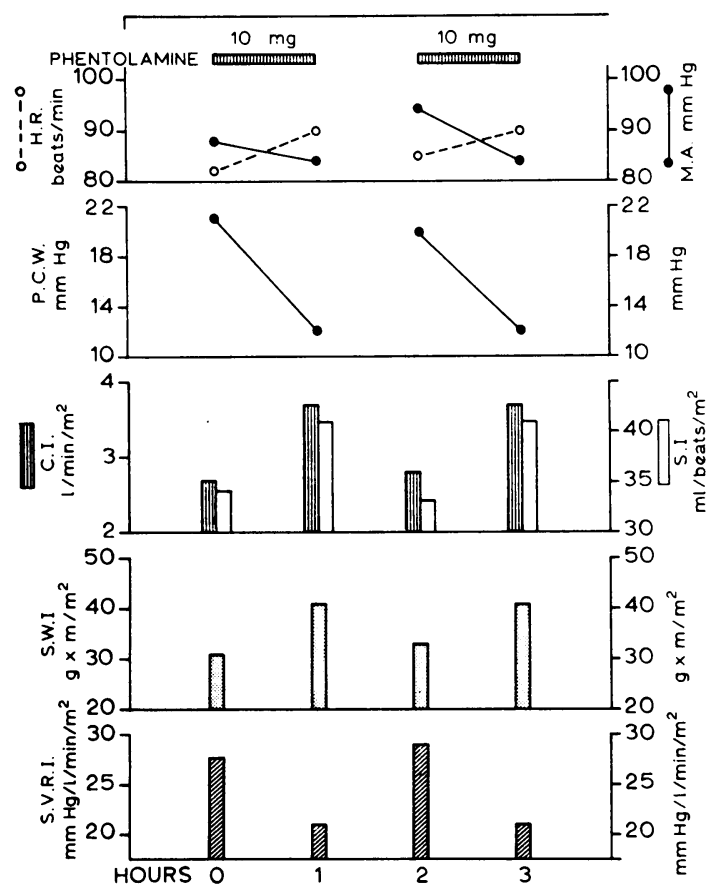

FIG. 3 Haemodynamic response to two successive perfusions of phentolamine showing the reproducibility of the effects (Case 6). (I $\mathrm{mmHg}=0.133 \mathrm{kPa}$.)

ciency, secondary to septal perforation, and the other as a result of ventricular fibrillation.

\section{Discussion}

This study indicates that administration of a small dose of phentolamine to patients in the acute phase of myocardial infarction, complicated by left ventricular failure, results in a reduction in the mean systemic arterial blood pressure and pulmonary wedge pressure, with an increase in the cardiac output. For the majority of the patients studied this meant an improvement in left ventricular performance, as shown by the fact that the left ventricular work was maintained or increased, at a lower filling pressure. Similar results have been published by other authors (Kelly et al., 1973; Chatterjee et al., 1973), though the doses used were generally higher. The present study also shows that the haemodynamic improvements are of short duration after cessation of the infusion and that subsequent infusions produce similar haemodynamic effects. The overall clinical course of the cases treated was satisfactory; the mortality rate of 13 per cent in this group of high risk patients was surprisingly low.
The haemodynamic changes observed after phentolamine are the opposite of those described by Ross and Braunwald (1964), following angiotensin administration in patients with non-ischaemic cardiac insufficiency. The response to an increase in afterload induced by angiotensin is characterized by an increase in left ventricular filling pressure and a decrease in stroke volume. This leads to ventricular dilatation and therefore to an increase in ventricular wall tension, which represents one of the factors determining oxygen consumption in the myocardium. This effect could theoretically be counterbalanced by the increased coronary perfusion pressure caused by increased aortic diastolic pressure. However, according to Maroko and Braunwald (1973) there is an optimal coronary perfusion pressure beyond which the increased oxygen requirement exceeds the increased supply, thus leading to relative ischaemia. It appears that in patients with myocardial infarction the optimal pressure is usually within the normal range of arterial blood pressure. It is probable that in these patients even a moderate increase in the impedance to ventricular ejection is sufficient to aggravate the imbalance between the oxygen supply and demand of the myocardium.

Acute arterial hypertension is common in the first few hours after infarction. It is classically ascribed to an intense sympathetic stimulation and to the release of catecholamines. The resulting increased peripheral vascular resistance has the effect of raising metabolic requirements by increasing the left ventricular wall tension. To this is added the oxygen wasting effect of catecholamines (Raab et al., 1962; Braunwald, 1971). Finally, it is possible that the rise in left ventricular diastolic pressure, if great enough, may impair the oxygen supply to the subendocardial area resulting in extension of the necrosis.

Therefore, under these conditions one may expect a reduction in the impedance to ventricular ejection to improve the myocardial performance and reduce the extent of myocardial damage by improving the balance between the coronary perfusion and the local metabolic requirements of the myocardium. If this is the case, then phentolamine would have the dual effect of preventing or correcting the heart failure, and possibly preventing extension of the necrosis. The effects of phentolamine on ventricular performance are explained essentially by its action on the resistance vessels, though not entirely. Phentolamine in fact combines antagonism toward catecholamines (alpha-blocking properties) with a direct action leading to relaxation of the smooth muscle of the vessels. This results in vasodilatation with a reduction in the systemic 
vascular resistance (Taylor et al., 1965; Nickerson, 1965). This reduction in the impedance to left ventricular ejection leads to a fall in pulmonary capillary pressure parallel to the fall in left ventricular end-diastolic pressure and consequently to a reduction in the residual ventricular volume (Cohn et al., 1972).

Furthermore, because of its relaxant effect on the venous tone (Abboud and Eckstein, 1968; Villani et al., 1974), phentolamine can induce a shift of blood volume to the periphery which could also lead to a further fall in left ventricular filling pressure. However, this mechanism only plays an accessory role, since the reduced preload obtained with tourniquets, bleeding, or diuretics, is itself accompanied by a reduction in cardiac output (Cohn et al., 1972).

There is no conclusive evidence that phentolamine has any inotropic effect (Chatterjee et al., 1973; Abboud and Eckstein, 1968), but the possibility that the fall in left ventricular end-diastolic pressure induced by phentolamine may indirectly improve the myocardial performance, by improving the subendocardial perfusion, cannot be excluded. Vasodilator therapy with phentolamine has no adverse effect on the overall myocardial oxygen metabolism, as may be seen from the absence of any significant reduction in the extraction of lactate by the myocardium (Chatterjee et al., 1973). This suggests that the effect of a possible reduction in coronary perfusion secondary to the fall in aortic pressure is largely compensated by the reduction in the oxygen requirement of the myocardium, resulting from the reduction in the afterload.

Vasodilator therapy with phentolamine is not necessarily reserved for hypertensive patients. In low doses (Io mg per hour) it has proved beneficial in normotensive subjects in whom the reduced cardiac output was masking the increased peripheral resistance. With such small doses it has never been necessary to discontinue the treatment as a result of arterial hypotension. It should, therefore, be emphasized that one of the principal advantages of phentolamine administered by infusion is its short duration of action, which renders it easily manageable. Nevertheless, such a therapeutic procedure should only be employed where haemodynamic monitoring facilities are available. In this respect, surveillance of the pulmonary wedge pressure is an extremely useful index for assessing the response to the treatment.

\section{References}

Abboud, F. M., and Eckstein, J. W. (1968). Vascular responses after alpha adrenergic receptor blockade. II. Responses of venous and arterial segments to adrenergic stimulation in the forelimb of dog. Fournal of Clinical Investigation, 47, 10.

Braunwald, E. (1971). Control of myocardial oxygen consumption. American fournal of Cardiology, 27, 4I6.

Chatterjee, K., Parmley, W. W., Ganz, W., Forrester, J., Walinsky, P., Crexells, C., and Swan, H. J. C. (1973). Hemodynamic and metabolic responses to vasodilator therapy in acute myocardial infarction. Circulation, 48, II83.

Cohn, J. N. (1973). Blood pressure and cardiac performance. American fournal of Medicine, 55, $35 \mathrm{I}$.

Cohn, J. N., Franciosa, J. A., Broder, M., Giuha, N., and Limas, C. J. (1972). Relative importance of preload and afterload as determinants of left ventricular performance in acute myocardial infarction (abstract). Fournal of Clinical Investigation, 51, 20a.

Cohn, J. N., Tristani, F. E., and Khatri, I. M. (1969). Cardiac and peripheral vascular effects of digitalis in clinical cardiogenic shock. American Heart fournal, 78, 318.

Dikshit, K., Vyden, J. K., Forrester, J. S., Chatterjee, K., Prakash, R., and Swan, H. J. C. (I973). Renal and extrarenal hemodynamic effects of furosemide in congestive heart failure after acute myocardial infarction. New England fournal of Medicine, 288, 1087.

Enrico, J.-F., Poli, S., and Perret, Cl. (I97I). La phentolamine dans le traitement de l'oedème pulmonaire aigu 'réfractaire'. Bulletin de Physio-Pathologie Respiratoire, 7, I319.

Franciosa, J. A., Giuha, N. H., Limas, C. J., Rodriguera, E., and Cohn, J. N. (1972). Improved left ventricular function during nitroprusside infusion in acute myocardial infarction. Lancet, $1,650$.

Ganz, W., and Swan, H. J. C. (1972). Measurement of blood flow by thermodilution. American fournal of Cardiology, 29, 24 I.

Hodges, M., Friesinger, G. C., Riggins, R. C. K., and Dagenais, G. R. (1972). Effects of intravenously administered digoxin on mild left ventricular failure in acute myocardial infarction in man. American fournal of Cardiology, 29, 749.

Kelly, D. T., Delgado, C. E., Taylor, D. R., Pitt, B., and Ross, R. S. (I973). Use of phentolamine in acute myocardial infarction associated with hypertension and left ventricular failure. Circulation, 47, 729.

Malmcrona, R., Schröder, G., and Werkö, L. (1966). Haemodynamic effects of digitalis in acute myocardial infarction. Acta Medica Scandinavica, 180, 55.

Majid, P. A., Sharma, B., and Taylor, S. H. (197I). Phentolamine for vasodilator treatment of severe heart-failure. Lancet, 2, 719.

Maroko, P. R., and Braunwald, E. (1973). Modification of myocardial infarction size after coronary occlusion. Annals of Internal Medicine, 79, 720.

Nickerson, M. (1965). Drugs inhibiting adrenergic nerves and structures innervated by them. In The Pharmacological Basis of Therapeutics, 3rd ed., p. 547. Ed. by L. S. Goodman and A. Gilman. Macmillan, New York.

Raab, W., Van Lith, P., Lepeschkin, E., and Herrlich, H. C. (I962). Catecholamine-induced myocardial hypoxia in the presence of impaired coronary dilatability independent of external cardiac work. American fournal of Cardiology, 9, 455.

Rahimtoola, S. H., Sinno, M. Z., Chuquimia, R., Loeb, H. S., Rosen, K. M., and Gunnar, R. M. (1972). Effects of ouabain on impaired left ventricular function in acute myocardial infarction. New England fournal of Medicine, 287,527 . 
Ross, J., Jr., and Braunwald, E. (1964). The study of left ventricular function in man by increasing resistance to ventricular ejection with angiotensin. Circulation, 29, 739.

Taylor, S. H., Sutherland, G. R., Mackenzie, G. J., Staunton, H. P., and Donald, K. W. (I965). The circulatory effects of intravenous phentolamine in man. Circulation, 31, 74I.

Villani, F., Perret, C., Jéquier, E., and Schelling, J.-L.
(1974). Effect of phentolamine on peripheral venous distensibility in congestive heart failure. European fournal of Clinical Pharmacology, 7, 11.

Requests for reprints to Professor Cl. Perret, Département de Médecine, Hôpital Cantonal Universitaire, IoI I Lausanne, Switzerland. 